\title{
Chrysanthemum indicum ethanolic extract inhibits invasion of hepatocellular carcinoma via regulation of MMP/TIMP balance as therapeutic target
}

\author{
ZHI-DONG WANG ${ }^{1}$, CHEN HUANG $^{2}$, ZONG-FANG LI $^{1}$, JUN YANG $^{3}$, BAO-HUA LI ${ }^{1}$, \\ RONG-RUI LIANG ${ }^{1}$, ZHI-JUN DAI ${ }^{1}$ and ZHONG-WEI LIU ${ }^{1}$
}

\begin{abstract}
${ }^{1}$ Department of Surgery, The Second Affiliated Hospital, School of Medicine, Xi'an Jiaotong University, Xi'an, Shaanxi Province 710004; ${ }^{2}$ Key Laboratory of Environment and Genes Related to Diseases of the Education Ministry, School of Medicine, Xi'an Jiaotong University, Xi'an, Shaanxi Province 710061; ${ }^{3}$ Department of Pathology, The Second Affiliated Hospital, School of Medicine, Xi'an Jiaotong University, Xi'an, Shaanxi Province 710004, P.R. China
\end{abstract}

Received August 17, 2009; Accepted October 8, 2009

DOI: $10.3892 /$ or_00000650

\begin{abstract}
Hepatocellular carcinoma (HCC) is an aggressive cancer with a dismal outcome largely due to metastasis and postsurgical recurrence. Thus, the inhibition of invasion and metastasis is of great importance in its therapies. Medicinal plants or ethnopharmacology used in folklore medicine continue to be an important source of discovery and development of novel or potential therapeutic agents for treatment of cancer. Chrysanthemum indicum, one of the medicinal plants or ethnopharmacology, is being used for treatment of many diseases including cancer. However, this plant molecular mechanisms underlining the anti-metastatic effects have not been well documented. In this study, Chrysanthemum indicum ethanolic extract (CIE) significantly suppressed proliferation and invasion of MHCC97H cells, one of the HCC cell lines with high metastatic potential, in a dose-dependent manner. CIE markedly decreased MMP-2 and MMP-9 expression, increased simultaneously TIMP-1, and TIMP-2 expression further restoring their balance in the cancer cells. The present study indicates that CIE reduced $\mathrm{MHCC} 97 \mathrm{H}$ cell metastatic capability, in part at least, through decrease of the MMP expression, simultaneous increase of the TIMP expression, further restoring their balance as therapeutic target in HCC. It is suggested that Chrysanthemum indicum is a potential novel therapeutic medicinal plant for treatment of $\mathrm{HCC}$ or cancer invasion and metastasis.
\end{abstract}

Correspondence to: Professor Zong-Fang Li, Department of General Surgery, The Second Affiliated Hospital, School of Medicine, Xi'an Jiaotong University, Xi'an, Shaanxi Province 710004, P.R. China

E-mail: lzf2568@gmail.com

Key words: traditional Chinese medicine, Chrysanthemum indicum, invasion, hepatocellular carcinoma, MMPs, TIMPs

\section{Introduction}

Hepatocellular carcinoma (HCC) is one of the most common malignancies in China, where it ranks as the second leading cause of cancer mortality (1) and approximately accounts for half in the world $(2,3)$. Features of HCC are an aggressive cancer with a dismal outcome largely due to metastasis and postsurgical recurrence (4). Thus, the inhibition of invasion and metastasis is of great importance in the HCC therapies.

Tumor invasion and metastasis, which, respectively, refer to the spread and growth of cancer cells from a primary neoplasm to distant sites, represent a multistep process that depends on the activities of many factors associated with the proteolytic degradation of extracellular matrix (ECM) components (5). Matrix metalloproteinases (MMPs), a family of zinc-dependent endopeptidases, play a crucial role in ECM degradation associated with cancer cell invasion, metastasis and angiogenesis $(5,6)$. Among them, MMP-2 (gelatinase-A) and MMP-9 (gelatinase-B) are significantly up-regulated in malignant tumors and cause invasion and metastatic spread of cancer cells by degrading type IV collagen, a major component of the basement membrane. Activities of MMPs are controlled by their endogenous inhibitors, which are known as tissue inhibitor of metalloproteinases (TIMPs) such as TIMP-1 and TIMP-2 in cancer cells (7). It has been suggested that the balance of MMPs and TIMPs was broken. Therefore, direct inhibition of MMPs but increase of TIMPs in cancer could emerge as a particularly attractive target for therapeutic intervention in tumor invasion and metastasis.

Less effective management that decreases MMP expression, but increases simultaneously TIMP expression, and further reverses the imbalance between them in HCC invasion is currently available. Medicinal plants or ethnopharmacology used in folklore medicine continue to be an important source of discovery and development of novel or potential therapeutic agents in cancer proliferation and invasion (8-10), thereby indicating that medicinal plants or ethnopharmacology could exhibit anti-metastatic properties against MMP/TIMP imbalance of cancer. Particularly, in 
East Asia such as China, Korea, and Japan, abundant experience and substantial clinical data on the management of HCC invasion and metastasis have been documented with traditional Chinese medicine (TCM), especially medicinal plants, which have been developed over a period of thousands of years (11-13).

The Compositae plant, flowers of Chrysanthemum indicum (Chrysanthemi Indici Flos), one of the TCM and medicinal plants, is widely used in the treatment of hypertension, colitis, pneumonia and carbuncle in China. Mounting evidence indicates that Chrysanthemum indicum possesses antiinflammatory, antioxidant, immunomodulation and antimicrobial activities $(14,15)$. Accumulating evidence shows that Chrysanthemum indicum is capable of inhibiting proliferation of human PC3, HL 60 and HeLa cancer cells in a dose- and time-dependent manner (16). Furthermore, our previous study found that Chrysanthemum indicum extract (CIE) exerted significant apoptotic effect through the mitochondrial-dependent capase-3 pathway and arrested the cell cycle by regulation of cell cycle related proteins including P21 and CDK4 on MHCC97H cells without impairment of normal cells (17). Intriguingly, in clinic, Xiang et al (18) found that patients receiving Chrysanthemum indicum, as one of main components, combined with other TCM, a 5-year overall survival rate of $70 \%$ and a complete response rate of $60 \%$, and combination with chemotherapeutic agents, a 5-year overall survival rate of $77 \%$ and a complete remission rate of $80 \%$, were achieved, respectively, in postoperative patients with metastatic breast cancer without adverse effects. Bi et al (19) demonstrated that with Chrysanthemum indicum combined with TCM, a response rate of $67 \%$ were obtained in management of esophageal carcinoma patients with advanced stage, and without myelosuppression and toxicities of liver and kidneys. These studies suggest that Chrysanthemum indicum is one of novel anti-metastatic drugs with low toxicity and high efficacy. However, studies of anti-metastatic properties of this herb hardly exist.

In the present study, we investigated the anti-metastatic properties of CIE using the MHCC $97 \mathrm{H}$ cell line, a typical human HCC cells with high metastatic potential $(20,21)$ that highly expressed MMPs $(21,22)$, and commonly used in the study of antitumor invasion. Furthermore, we determined whether CIE inhibits the migration of $\mathrm{MHCC} 97 \mathrm{H}$ cells through a Matrigel-coated membrane, possible modulating the effects of CIE toward the expression of MMPs and TIMPs.

\section{Materials and methods}

Cell culture and reagents. Human MHCC97H, a HCC cell line with high metastatic potential, was obtained from Liver Cancer Institute of Fudan University (Shanghai, China). 3-(4, 5-dimethylthiazol-2-yl)-2, 5-diphenyltetrazo-lium bromide (MTT) was purchased from (Sigma Chemical Co., St. Louis, MO). DMEM, fetal bovine serum (FBS) and Trypsin was obtained from (Gibco BRL, Grand Island, NY, USA). AntiMMP-2 and MMP-9, and anti- $\beta$-actin were purchased from Cell Signaling Technology (Beverly, MA, USA). AntiTIMP-1 and TIMP-2 were purchased from Biosynthesis
Biotechnology Company (Beijing, China). MHCC97H cells were cultured in DMEM supplemented with $10 \%$ FBS, growth in a $37^{\circ} \mathrm{C}$ humidified incubator containing $5 \% \mathrm{CO}_{2}$ and $95 \%$ subcultured with $0.25 \%$ Trypsin- $0.02 \%$ EDTA.

Preparation of Chrysanthemum indicum extract. The high quality flowers of Chrysanthemum indicum were dried under sunlight for 2 days, and processed for powder. As described in detail previously (17), briefly, the powdered herbs were extracted twice with $95 \%$ ethanol (with $2 \mathrm{~h}$ reflux), and the extract was then concentrated under reduced pressure. The concentrated extract was filtered, lyophilized, and stored at $-20^{\circ} \mathrm{C}$. The yield of dried extract from starting crude materials was $13.3 \%$. The lyophilized powder was dissolved in phosphate buffered solution (PBS) and then filtered through a $0.2-\mu \mathrm{m}$ syringe filter.

Cell inhibition assay. MHCC97H cells were seeded into 96well plates at a density of $5 \times 10^{4} /$ well. For the cell inhibition assay, cells were incubated with different concentrations of CIE $200,400,800,1200,1600 \mu \mathrm{g} / \mathrm{ml}$ or vehicle alone for $24 \mathrm{~h}$, following by a MTT assay as described (23). After $24 \mathrm{~h} \mathrm{MTT}$ solution $(5 \mathrm{mg} / \mathrm{ml})$ was then added to each well, and the plates were further incubated at $37^{\circ} \mathrm{C}$ for $4 \mathrm{~h}$ in a humidified incubator with $5 \% \mathrm{CO}_{2}$. At the end of incubation period, the medium was discarded and $200 \mu 1 \mathrm{DMSO} /$ well was added to a 96-well plate to solubilize formazan crystals. The optical density was determined at $570 \mathrm{~nm}$ with a microplate autoreader (Biotech Instruments, VT, USA).

Invasion assays. Briefly, as described previously (24), matrigel-coated filter inserts $(8 \mu \mathrm{m}$ pore size) that fit into $24-$ well invasion chambers were obtained from Becton-Dickinson (NJ, USA). MHCC97H cells were resuspended in conditioned medium $\left(5 \times 10^{4}\right.$ cells $\left./ 200 \mu 1\right)$, and then added to the upper compartment of the invasion chamber in the presence of various concentration of CIE $(400,800,1200 \mu \mathrm{g} / \mathrm{ml})$ or vehicle. Conditioned medium $(500 \mu \mathrm{l})$ was added to the lower compartment and was incubated at $37^{\circ} \mathrm{C}$ for $24 \mathrm{~h}$ in $5 \%$ $\mathrm{CO}_{2}$. After incubation, the cells on the upper side of the filter were removed using cotton swabs and were fixed, mounted and stained according to the manufacturer's instructions. Cells that invaded through the matrigel and were located on the underside of the filter were counted. Three to five invasion chambers were used per condition. The values obtained were calculated by averaging the total number of cells from three filters.

Immunofluorescent staining of MHCC97H cells. To detect the effect of CIE on MMP-2, MMP-9, TIMP-1 and TIMP-2 expression in MHCC97H cells, the cells were pretreated with CIE $(800 \mu \mathrm{g} / \mathrm{ml})$ for $24 \mathrm{~h}$. After the treatment, the cells were fixed with $4 \%$ formaldehyde-PBS for $15 \mathrm{~min}$. The cell membranes were fenestrated with $0.3 \%$ Triton-100-PBS, and nonspecific binding sites were blocked with $10 \%$ goat serum. The cells were incubated with rabbit anti-human MMP-2 and MMP-9 (1:400) or anti-human TIMP-1 and TIMP-2 antibody $(1: 200)$ at $4^{\circ} \mathrm{C}$ overnight and then incubated with the appropriate fluorescence-labeled secondary antibody conjugated to fluorescein isothiocyanate (FITC) at room 
temperature for $1 \mathrm{~h}$. The immunolabeled cells were observed under fluorescence confocal microscopy (Leica TCS SP2AOB).

Isolation of RNA and semiquantitative RT-PCR. When $1 \times 10^{6}$ MHCC $97 \mathrm{H}$ were incubated with various concentrations of CIE $(400,800,1200 \mu \mathrm{g} / \mathrm{ml})$ or vehicle for $24 \mathrm{~h}$, total cellular RNA was isolated from cells using the TRIzol kit (Takara, Biomedicals), as reported previously (25). Total RNA $(2 \mu \mathrm{l})$ was reverse transcribed to $10 \mu 1 \mathrm{cDNA}$ with $1 \mathrm{mM}$ oligo (dT), $0.5 \mathrm{mM}$ dNTP, $50 \mathrm{mM}$ Tris- $\mathrm{HCl}$ (pH 8.3), $75 \mathrm{mM} \mathrm{KCl}$, $3 \mathrm{mM} \mathrm{MgCl}_{2}, 1$ unit RNase inhibitor. The PCR reaction proceeded in 'Ready To Go' PCR Beads (Takara, Biomedicals). The PCR cycles were $94^{\circ} \mathrm{C}$ for $5 \mathrm{~min}, 58^{\circ} \mathrm{C}$ for $2 \mathrm{~min}$, and $72^{\circ} \mathrm{C}$ for $3 \mathrm{~min}$. The PCR products (179-bp ß-actin fragment; 498-bp MMP-2 fragment; 204-bp MMP-9 fragment; 276-bp TIMP-1 fragment; 430-bp TIMP-2 fragment) were eletrophoresed on $1.5 \%$ agarose gel after 30 cycles and visualized by ethidium bromide staining. Amplification of $ß$-actin served as a control for sample loading and integrity. The sense and anti-sense primer sequences were B-actin: ATCGTGCGTGACTTAAGGAG and GGAAGGAAGGCT GGAAGAG; MMP-9: GACGCCGCTCACTTACTC and GGAACCACGACGCCCTTGC; MMP-2: CAAGTGGTCC TGTAATATGG and GTCATCATCGTAGTTGGCTGTGG; TIMP-1: GTTGTGCGTGGCGATAG and TGTGGGACC TGTGGAGTA; TIMP-2: CACCCACAGACGGCCTTCTG CAAT and AGTGTAGGTCTTGGTGAAGCC.

Western blotting. MHCC $97 \mathrm{H}$ cells $\left(1 \times 10^{6} /\right.$ well) were treated with CIE $(400,800$, and $1200 \mu \mathrm{g} / \mathrm{ml})$ or vehicle for an appropriate time. For MMP-2, MMP-9, TIMP-1 and TIMP-2 Western blotting, as described previously (25), cells were lysed in a sample buffer followed by denaturation. Protein concentration was measured using Bradford assay and equal amounts of protein $(50 \mu \mathrm{g})$ were subjected to SDS-PAGE on $12 \%$ gel. The proteins were then electrophoretically transferred to nitrocellulose membranes. Membranes were first blocked with $5 \%$ nonfat dry milk/PBS $+0.1 \%$ Tween-20 (W/V) and immunolabelled using primary antibodies. Goat anti-rabbit HRP conjugated antibodies (Cell Signaling Technology) were used as secondary antibodies and detected with enhanced chemiluminescence (ECL) (Amersham, USA). Equal loading of each lane was evaluated by immunoblotting the same membranes with $B$-actin antibodies after detachment of previous primary antibodies. Photographs were taken and optical densities of the bands were scanned and quantified with the Gel Doc 2000 (Bio-Rad).

Gelatin zymography analysis on the enzyme activities of MMP-2 and MMP-9. Gelatin zymography was performed as described previously (26). Briefly, MHCC97H cancer cells treated with CIE $(400,800$, and $1200 \mu \mathrm{g} / \mathrm{ml})$ or without were incubated in serum-free medium for $24 \mathrm{~h}$. Then the samples of conditioned media were collected and diluted in a sample buffer containing and loaded without boiling separating gel containing $0.1 \%(\mathrm{~W} / \mathrm{V})$ gelatin. After electrophoresis with a constant voltage of $100 \mathrm{~V}$, the gels were soaked in $0.25 \%$ Triton X-100 (2 times for $30 \mathrm{~min}$ ) at room temperature and rinsed in distilled water. The gel slab was cut into slices

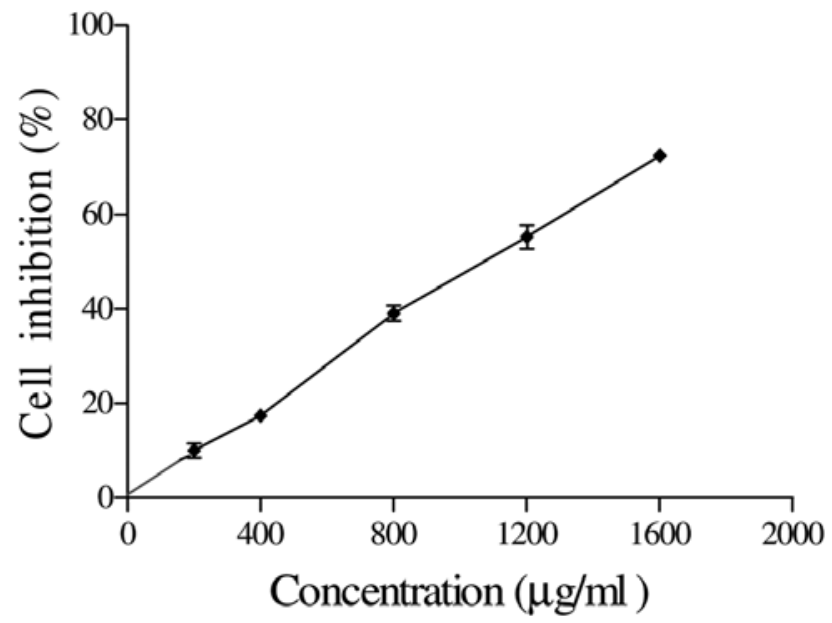

Figure 1. Anti-proliferative effect of Chrysanthemum indicum ethanolic extract (CIE) on MHCC $97 \mathrm{H}$ cells at $5 \times 10^{4}$ cells/well which were cultured with CIE $(200,400,800,1200,1600 \mu \mathrm{g} / \mathrm{ml})$ in DMEM-10\% fetal bovine serum for $24 \mathrm{~h}$. Cells proliferation were assayed by MTT. Values represent means \pm SEM from three independent experiments.

corresponding to the lanes and incubated at $37^{\circ} \mathrm{C}$ for $24 \mathrm{~h}$ in an incubation buffer. The gel was then stained for $30 \mathrm{~min}$ in $0.1 \%$ (W/V) Coomassie blue R-250 in 30\% methanol and $10 \%$ acetic acid, and destained in the same solution without the Coomassie blue dye. Proteolysis was detected as a white zone in a dark field, and the intensity of the bands obtained from the zymogram studies was estimated with a Scion Image instrument (Scion Corp., MD, USA).

Reverse zymography analysis on the enzyme activities of TIMP-1 and TIMP-2. Reverse zymography was used to detect TIMP-1 and TIMP-2 activity as described previously (27). Briefly, after MHCC97H cancer cells treated with CIE (400, 800 , and $1200 \mu \mathrm{g} / \mathrm{ml}$ ) or without were incubated in serumfree medium for $24 \mathrm{~h}$, equal protein concentrations of conditional culture medium were then subjected to SDS-10\% polyacrylamide gel electrophoresis on gels containing $1 \mathrm{mg} /$ $\mathrm{ml}$ of gelatin. After electrophoresis was completed, gels were washed in $2.5 \%$ Triton X-100 and incubated for $1 \mathrm{~h}$ at $37^{\circ} \mathrm{C}$ with conditioned media from phorbol 12-myristate 13-acetate (PMA)-activated MHCC97H cells, containing a mixture of activated MMPs. Then gels were incubated with $50 \mathrm{mM}$ Tris$\mathrm{HCl}, 50 \mathrm{mM} \mathrm{NaCl}, 10 \mathrm{mM} \mathrm{CaCl}_{2}$, and $0.05 \%$ Brij for $18 \mathrm{~h}$ at $37^{\circ} \mathrm{C}$, stained with Coomassie blue, and destained in acetic $\mathrm{acid} / \mathrm{methanol}$. Under these conditions, TIMPs inhibit gelatin digestion by activating MMP sand produce dark blue bands against a bright background. For quantification, densitometric scanning was performed by using a Bio-Rad GS 690 Image Analysis software system.

Statistical analysis. All measurements were performed in triplicate and repeated 3 times. Results are expressed as means \pm SEM. Data were analyzed using ANOVA and Dunnett's multiple comparison tests. $\mathrm{P}<0.05$ was considered significant. 

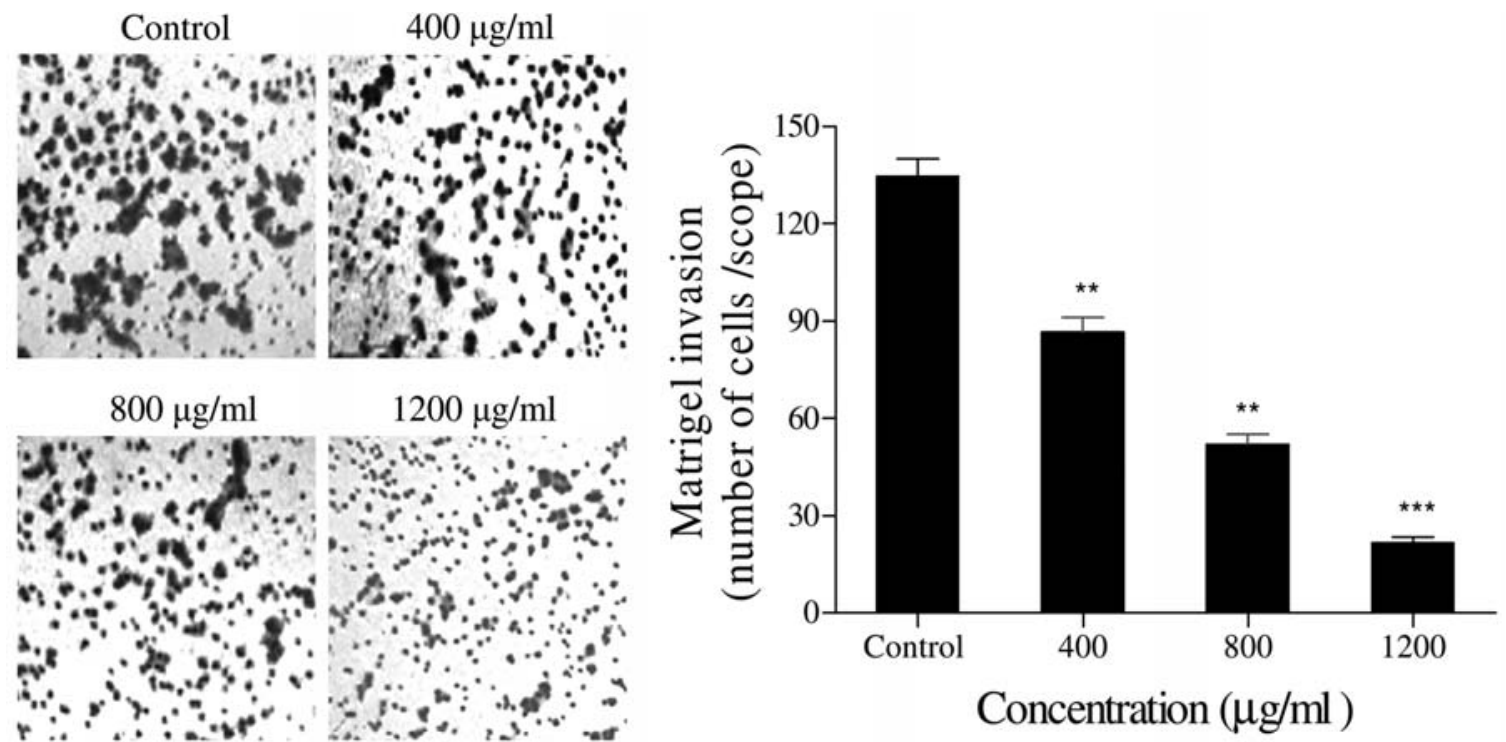

Figure 2. Effect of CIE on MHCC97H cells invasion at 5x10 cells/200 $\mu 1$ cultured with or without CIE (400, 800, and $1200 \mu \mathrm{g} / \mathrm{ml})$ in DMEM-10\% fetal bovine serum for $24 \mathrm{~h}$. Cell invasion was determined by transwell assay. Values represent means \pm SEM from three independent experiments $\left({ }^{* *} \mathrm{P}<0.01\right.$, ${ }^{* * *} \mathrm{P}<0.001$ vs. control group).

A

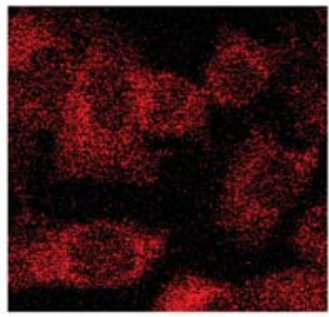

Control

B

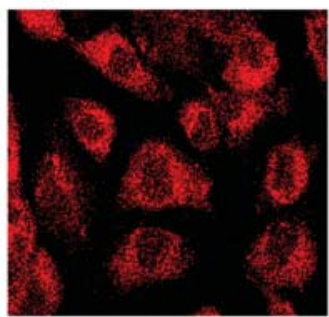

Control

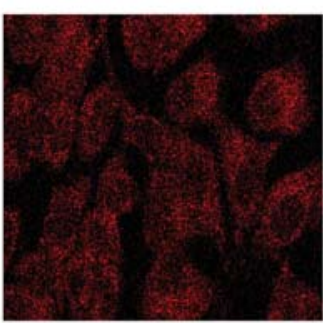

$800 \mu \mathrm{g} / \mathrm{ml}$

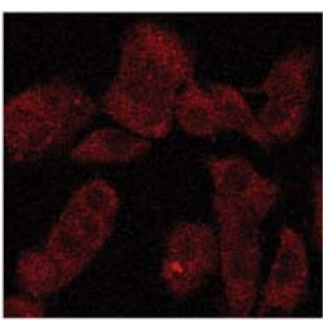

$800 \mu \mathrm{g} / \mathrm{ml}$
C

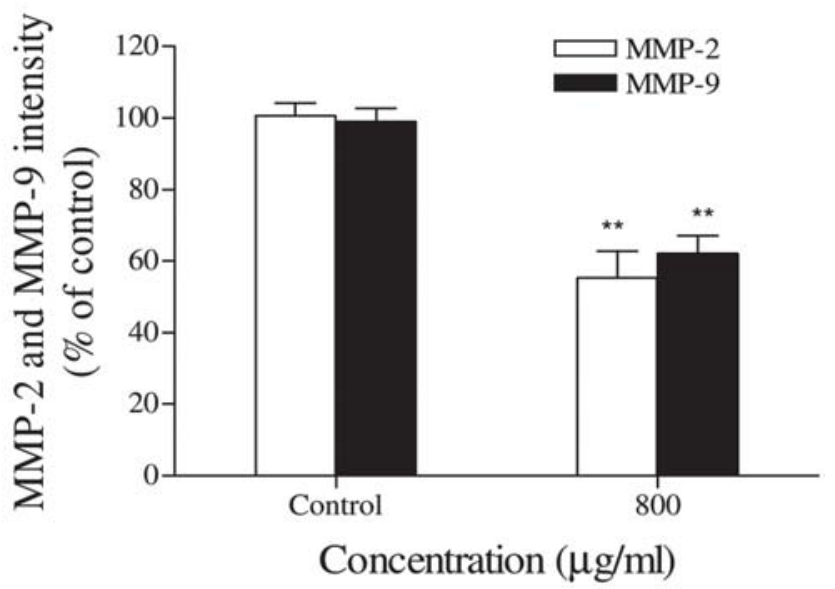

Figure 3. Immunofluorescence analysis of MMP-2 and MMP-9 expression in CIE treated MHCC97H cells or without. MHCC97H cells were pretreated for 24 $\mathrm{h}$ with concentrations of $800 \mu \mathrm{g} / \mathrm{ml} \mathrm{CIE}$ and then expression of MMP-2 (A) and MMP-9 (B) was identified with immunocytofluorescence and observed by confocal microscope. Fluorescence intensity of MMP-2 and MMP-9 was also detected (C). Values represent means \pm SEM from three independent experiments $\left({ }^{* *} \mathrm{P}<0.01\right.$ vs. control group).

\section{Results}

CIE inhibited proliferation in HCC cells. In this study, the effect of CIE on cell proliferation toward MHCC97H cells was measured by MTT assay. The effects of $200-1600 \mu \mathrm{g} / \mathrm{ml}$ CIE on cell growth after $24 \mathrm{~h}$ are shown in Fig. 1. After $24 \mathrm{~h}$ of incubation, CIE significantly suppressed MHCC $97 \mathrm{H}$ cell growth in a concentration-dependent manner with cell numbers markedly reduced compared to control. CIE at various concentrations significantly increased inhibition of cell proliferation compared with control, by $12.8,19.2,41,59$, and $74.3 \%$, respectively.

CIE attenuated HCC cell invasion. The potential effect of CIE on cell migration was tested by counting MHCC $97 \mathrm{H}$ cells that migrated through the Matrgel coated-membrane. As shown in Fig. 2, cell migrations were 86.7 $\pm 7.5,52 \pm 5.6$, $21.7 \pm 3.1$ in $400,800,1200 \mu \mathrm{g} / \mathrm{ml}$ dose of CIE, respectively, 
A

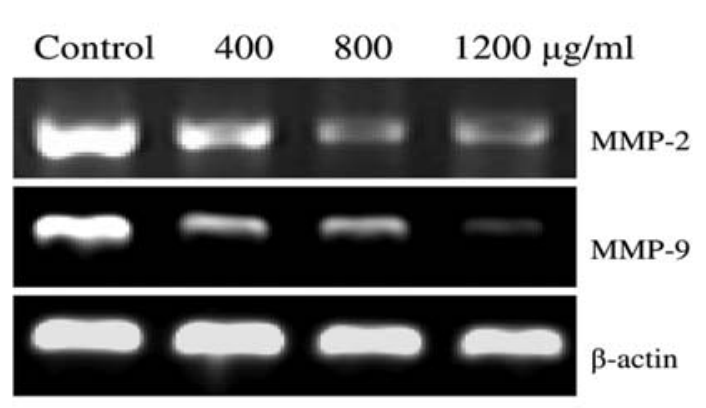

B

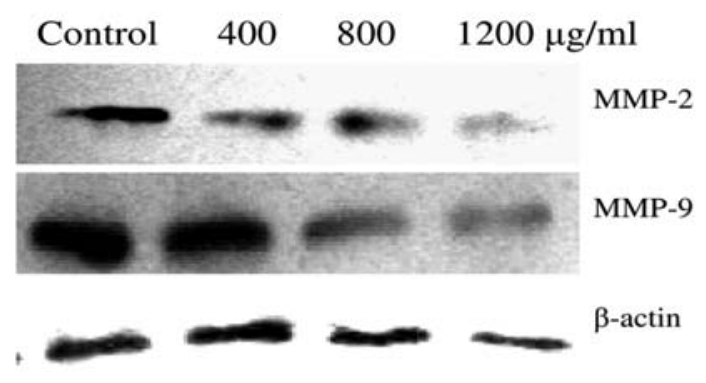

$\mathrm{C}$

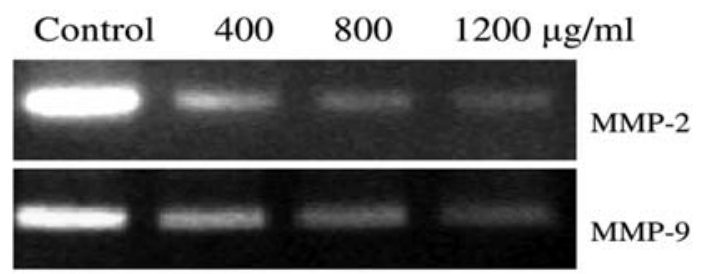

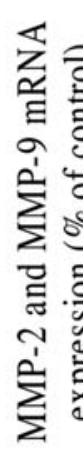

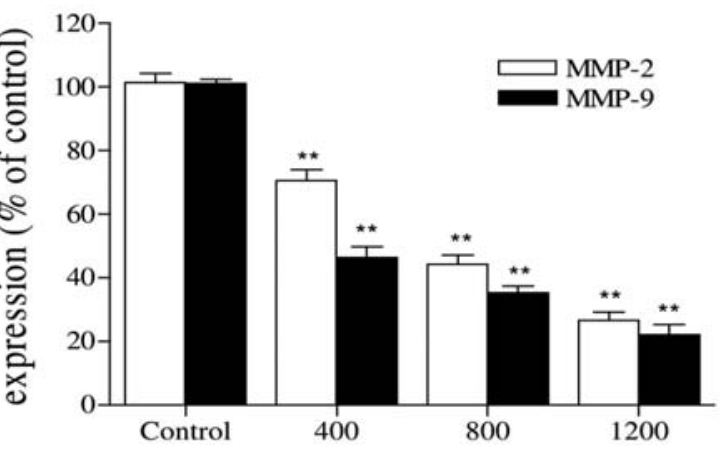

Concentration $(\mu \mathrm{g} / \mathrm{ml})$

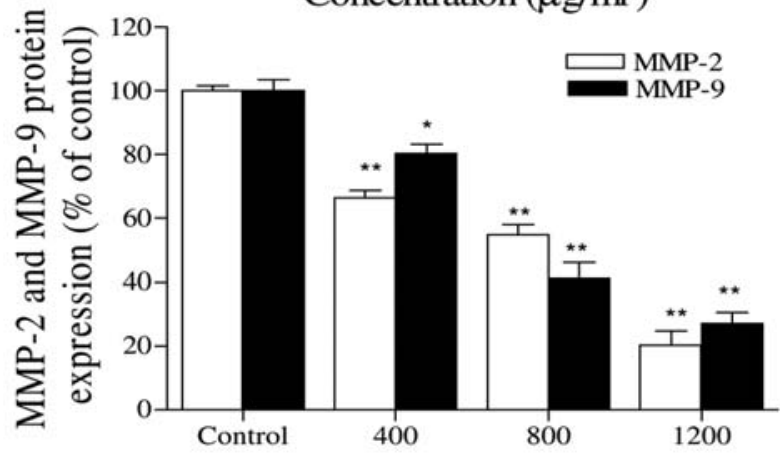

Concentration $(\mu \mathrm{g} / \mathrm{ml})$

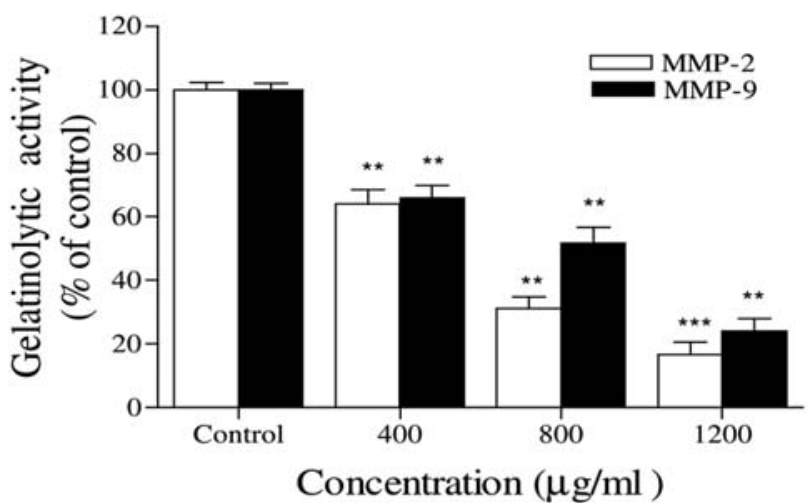

Figure 4. Effect of CIE on MMP-2 and MMP-9 mRNA, protein and enzyme activity in MHCC97H cells. MHCC97H cells (1x106 cells/well) were incubated for $24 \mathrm{~h}$ with CIE (400, 800, and $1200 \mu \mathrm{g} / \mathrm{ml})$ or without. The mRNA (A), protein (B) and enzyme activity (C) expression of MMP-2 and MMP-9 were determined by RT-PCR, Western blot and gelatin zymography analysis. Values represent means \pm SEM from three independent experiments $\left({ }^{*} \mathrm{P}<0.05\right.$, ${ }^{* *} \mathrm{P}<0.01,{ }^{* * *} \mathrm{P}<0.001$ vs. control group).

whereas control group was $134.7 \pm 9.3$. A significant decrease in the number of cancer cells migrating through the filters was observed after treatment with CIE (400, 800 and $1200 \mu \mathrm{g} / \mathrm{ml})$ for $24 \mathrm{~h}(\mathrm{P}<0.01)$. Furthermore, lesser cell counts were found along with the higher dosage of herbs added when MHCC97H cells were incubated with an increased dose of CIE.

CIE reduces $M M P-2$ and MMP-9 expression in $M H C C 97 H$ cells with luciferase assay. On the basis of the abovementioned cell invasion results, we tested the effect of CIE on the expression of MMP-2 and MMP-9 to investigate their possible action mechanisms of antimetastasis. The cells were pretreated with concentrations of CIE $(800 \mu \mathrm{g} / \mathrm{ml})$ for $24 \mathrm{~h}$, and then MMP-2 and MMP-9 expression was identified with immunocytofluorescence and observed by confocal microscope. Compared with control group (100\%), MMP-2 and MMP-9 expression was suppressed by $38 \%$ and $55 \%$, respectively, by treatment with CIE at $800 \mu \mathrm{g} / \mathrm{ml}$ (Fig. 3, $\mathrm{P}<0.01)$.

CIE decreased MMP-2 and MMP-9 $m R N A$, protein and enzyme activity expression. Prompted by the above-mentioned results with the immunofluorescent method, we further analyzed the effect of CIE on MMP-2 and MMP-9 mRNA, protein and enzyme activity expression in MHCC97H cells. When MHCC97H cells were incubated with CIE (400, 800 and $1200 \mu \mathrm{g} / \mathrm{ml}$ ) or without for $24 \mathrm{~h}$, the amount of MMP-2 and MMP-9 mRNA, protein and enzyme activities was measured by RT-PCR, Western blotting and gelatin zymography, respectively. These results showed that CIE markedly suppressed MMP-2 and MMP-9 mRNA, protein 
A

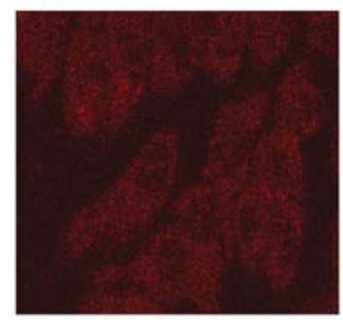

Control

B

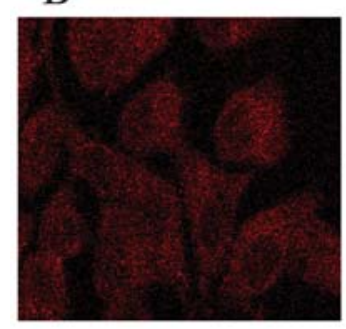

Control

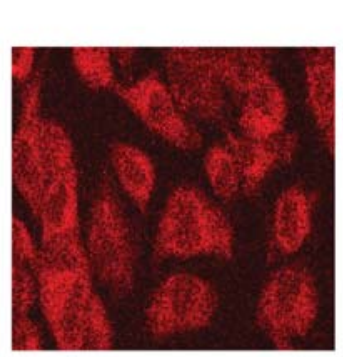

$800 \mu \mathrm{g} / \mathrm{ml}$

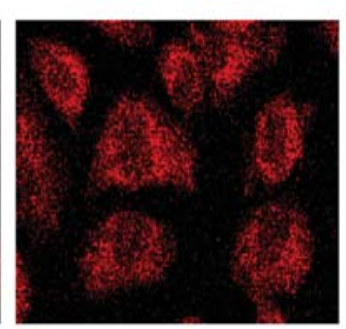

$800 \mu \mathrm{g} / \mathrm{ml}$
$\mathrm{C}$

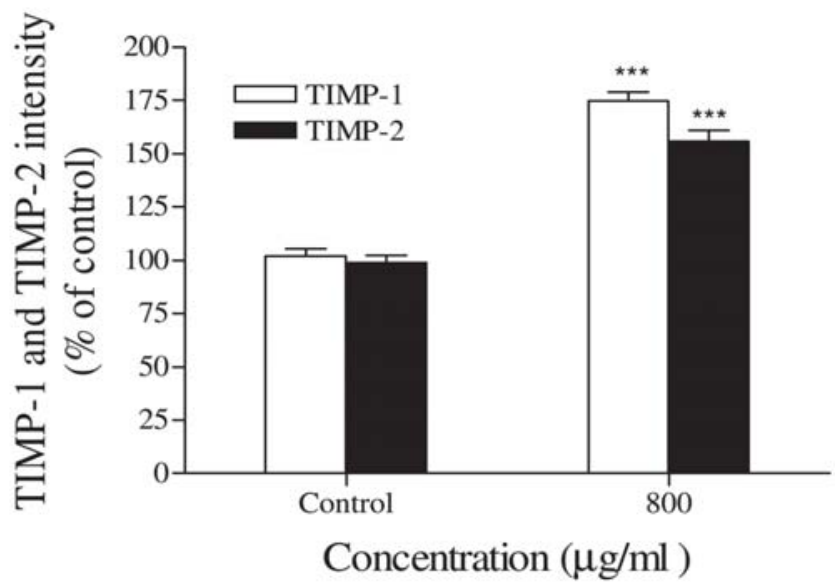

Figure 5. Immunofluorescence analysis of TIMP-1 and TIMP-2 expression in CIE treated MHCC97H cells or without. MHCC97H cells were pretreated for $24 \mathrm{~h}$ with concentrations of $800 \mu \mathrm{g} / \mathrm{ml} \mathrm{CIE}$ and then expression of TIMP-1 (A) and TIMP-2 (B) were identified with immunocytofluorescence and observed by confocal microscope. Fluorescence intensity of TIMP-1 and TIMP-2 was also detected (C). Values represent means \pm SEM from three independent experiments $\left({ }^{* * *} \mathrm{P}<0.001\right.$ vs. control group).

and enzyme activity in a dose-dependent manner (Fig. 4, $\mathrm{P}<0.05)$. CIE at $1200 \mu \mathrm{g} / \mathrm{ml}$ inhibited MMP-2 and MMP-9 mRNA expression by $31.5 \%$ and $26 \%$, reducing their protein expression by $27.6 \%$ and $33.8 \%$, and attenuated their activity by $16.8 \%$ and $24.1 \%$, respectively.

CIE promotes TIMP-1 and TIMP-2 expression in $M H C C 97 H$ cells with luciferase assay. As mentioned above, CIE is able to decrease the MMP-2 and MMP-9 production. To confirm whether CIE inhibits MMPs production via increasing TIMP expression, expression of TIMP-2 and TIMP-9 in MHCC97H cells were also identified with immunofluorescent staining and observed by confocal microscope. Representative graphs from each group are shown in Fig. 5. Compared with the control group (100\%), stronger TIMP-1 (175\%) and TIMP-2 $(156 \%)$ staining in the cytoplasm were seen in treatment with CIE concentrations of $800 \mu \mathrm{g} / \mathrm{ml}$ for $24 \mathrm{~h}(\mathrm{P}<0.001)$.

CIE increases TIMP-1 and TIMP-2 $m R N A$, protein and enzyme activity expression. TIMPs are preferably bound to the active center and inhibit MMP protease activity, thereby suppressing tumor invasion and metastasis. The balance between both molecules finally determines the net proteolytic activity. To examine whether CIE had decreased MMPs and increased simultaneously the expression and activity of their natural inhibitors or not, we tested both TIMP-1 and TIMP-2 mRNA, protein and enzyme activities. As shown in Fig. 6A and $\mathrm{B}$, there was a significant increase in TIMP-1 and TIMP-2 mRNA, protein expression in MHCC97H cells treated with 400, 800 and $1200 \mu \mathrm{g} / \mathrm{ml} \mathrm{CIE}$ in comparison with the control group $(\mathrm{P}<0.05)$. In addition, to test whether $\mathrm{CIE}$ also affects TIMP-1 and TIMP-2 enzyme activity, we performed reverse zymography analysis. The amount of enzyme activity for
TIMP-1 and TIMP-2 were dramatically enhanced with CIE in a concentration-dependent manner (Fig. 6C, $\mathrm{P}<0.05$ ). Specifically, CIE at $1200 \mu \mathrm{g} / \mathrm{ml}$ increased TIMP-1 and TIMP2 mRNA expression by $203 \%$ and $367 \%$, enhanced their protein expression by $219 \%$ and $244 \%$, and improved their activity by $98 \%$ and $99 \%$, respectively.

Effect of CIE on restoring the MMP-TIMP expression imbalances in $\mathrm{MHCC} 97 \mathrm{H}$ cells. Several investigations suggest that the imbalance of MMPs/TIMPs could contribute to cancer invasion and metastasis and the poor prognosis. To verify whether CIE could act on MMPs/TIMPs of cancer cells, we tested the expression ratio of MMPs:TIMPs in MHCC97H cells treated with CIE (0, 400, 800 and 1200 $\mu \mathrm{g} / \mathrm{ml})$. As shown in Fig. 7, the mRNA, protein, and enzyme activity levels of MMP-2 and MMP-9 significantly decreased in 400-1200 $\mu \mathrm{g} / \mathrm{ml}$ group when compared with the untreated group. However, the mRNA, protein, and enzyme activity levels of TIMP-1 and TIMP-2 were also increased simultaneously under $400-1200 \mu \mathrm{g} / \mathrm{ml}$ conditions. Therefore, in contrast to control group, the ratio of MMP:TIMP, as shown representatively in MMP-2/TIMP-2 and MMP-9/ TIMP-1, reduced followed by the increased concentration of CIE $(\mathrm{P}<0.05)$.

\section{Discussion}

Emerging studies report that CIE can inhibit proliferation of cancer cells, induce cell apoptosis including in HCC cells $(16,17)$ and have shown anti-metastatic properties in clinic without side effects $(18,19)$. CIE with low toxicity and high efficacy, one of the most active fields in cancer research, has been identified by our study (17) and clinical testing $(18,19)$. 
A
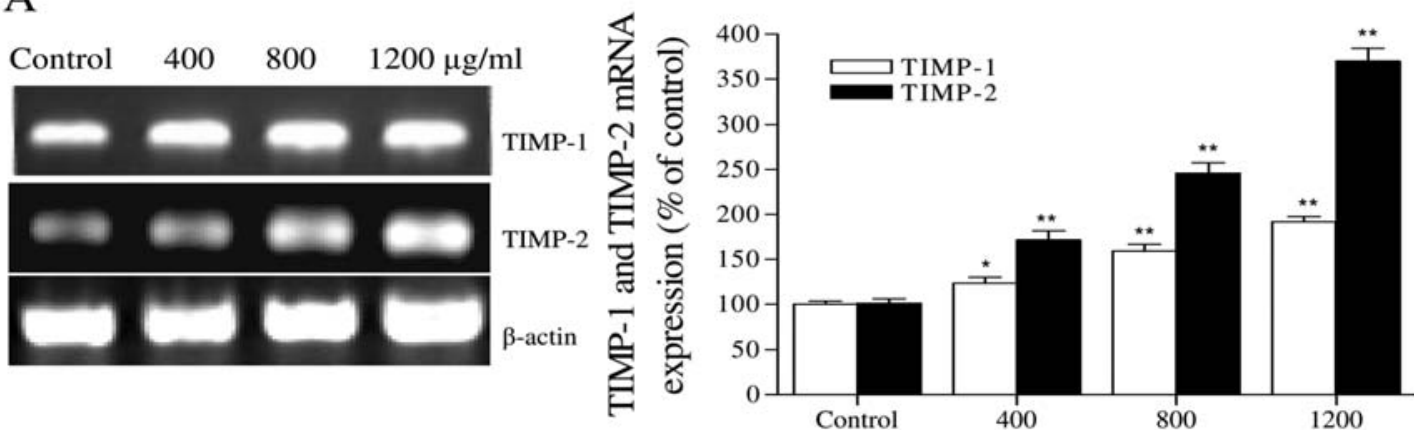

B

Concentration $(\mu \mathrm{g} / \mathrm{ml})$
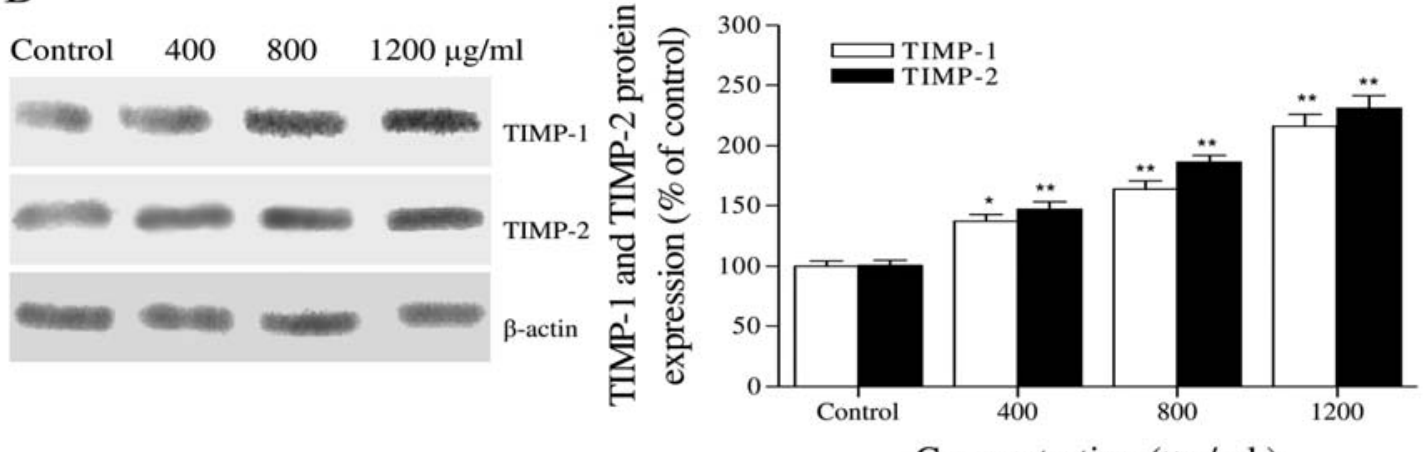

$\mathrm{C}$
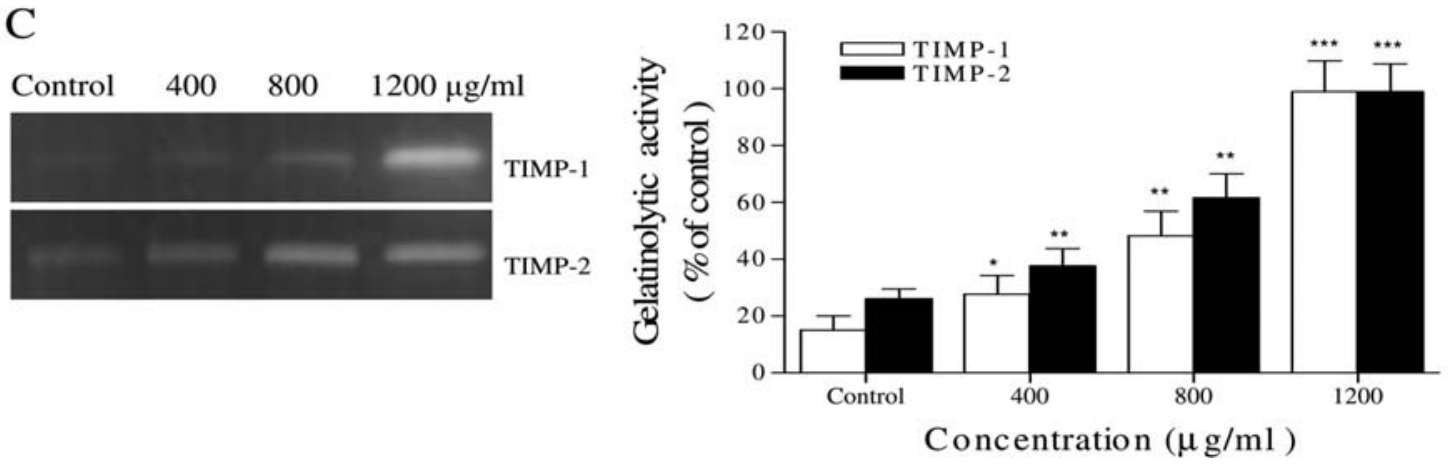

Figure 6. Effect of CIE on TIMP-1 and TIMP-2 mRNA, protein and enzyme activity expression in MHCC97H cells. MHCC97H cells (1x106 cells/well) were incubated for $24 \mathrm{~h}$ with CIE $(400,800$, and $1200 \mu \mathrm{g} / \mathrm{ml})$ or without. The mRNA (A), protein (B) and enzyme activity (C) expression of TIMP-1 and TIMP-2 were determined by RT-PCR, Western blot and reverse gelatin zymography analysis. Values represent means \pm SEM from three independent experiments $\left({ }^{*} \mathrm{P}<0.05,{ }^{* *} \mathrm{P}<0.01,{ }^{* * *} \mathrm{P}<0.001\right.$ vs. control group $)$.

A

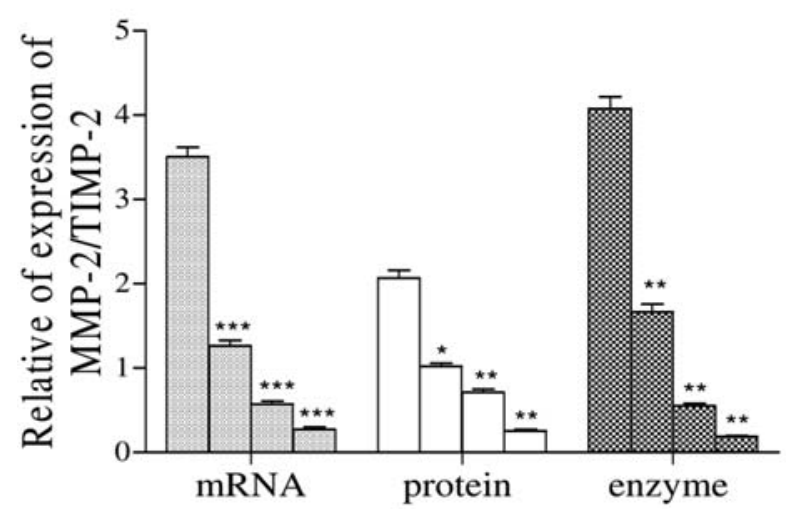

B

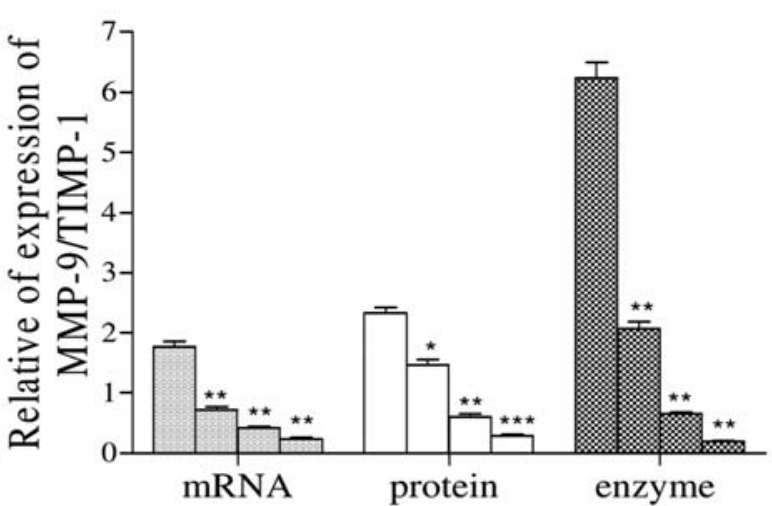

Figure 7. Effect of CIE on restoring the disoriented MMP and TIMP expression balances in MHCC $97 \mathrm{H}$ cells. After MHCC97H cells were incubated for $24 \mathrm{~h}$ with CIE $(400,800$, and $1200 \mu \mathrm{g} / \mathrm{ml})$ or without, the relative expressions of MMPs and TIMPs were detected. Then the ratio values of MMPs/TIMPs in mRNA, protein expression and enzyme activity were calculated. Values represent means \pm SEM from three independent experiments $\left({ }^{*} \mathrm{P}<0.05,{ }^{* *} \mathrm{P}<0.01\right.$, ${ }^{* * *} \mathrm{P}<0.001$ vs. control group). 
However, its molecular mechanisms underlining the antimetastatic effects have not been well documented. In our experiments, as shown in Fig. 1, CIE has a significant inhibition of viability effect on MHCC97H cells. Further investigations verified that CIE significantly decreased the migration of MHCC97H cells through a Matrigel-coated membrane (Fig. 2), indicating that CIE had a potent antimetastatic effect. Although the detailed mechanisms of metastasis has not been completed elucidated, the involvement of MMPs and TIMPs have been implicated.

Proteolysis of ECM components has been widely documented to be a critical step in the tumor metastasis cascade. Although the breakdown of ECM is achieved by several MMPs, notably the gelatinases or type IV collagenase MMP-2 and MMP-9 appear more important to ECM. Additionally, accumulating studies have demonstrated that activity of type IV collagenase (MMP-2 and MMP-9) is the highest in HCC with metastasis, and elevated serum levels of type IV collagenase reflect and predict potential of invasion and metastasis in patient with HCC (28-30). Furthermore, overexpression of MMP-2 or MMP-9 exacerbates the ECM degrading of invasive HCC cancer, whereas their inhibition has been reported to attenuate the ECM degraded process $(26,31,32)$, proposing that MMPs act as induced metastasis in cancer. In the present study, as shown in Figs. 3 and 4, CIE significantly reduced mRNA, and protein activity of MMP-2 and MMP-9 in MHCC97H cells, suggesting that the inhibited effect of CIE on HCC invasion is likely attributable to its antiMMP properties. Moreover, previously, several natural plants including TCM, Chai-hu-jia-longgu-mu-li-tang (31), Euonymus alatus extract (24), and Magnolia officinalis extract (33), have exhibited a potent anti-invasive inhibition of the gelatinolytic activities such as MMP-9 and MMP-2 expression properties in cancer cells. Thus far, however, it is unknown whether herbs or medicinal plants are able to attenuate MMP expression, but promote simultaneously TIMP expression and further restore the MMP/TIMP balance.

MMP activity, however, is inhibited by TIMPs so that an extensive degradation is avoided. In contrast, serum and tissue levels including HCC tissue and nodules, and TIMPs were significantly higher in hepatocellular carcinoma patients without metastasis than in those with metastasis (32). Therefore, the role of TIMPs is intriguing, not only in view of its involvement in the MMP activation process, but also because of its inhibitory function of MMP proteolytic activity. Among the members of the TIMP family, particularly TIMP-1 and TIMP-2, can inhibit tumor growth, invasion and metastasis, and also suppress MMP expression $(27,30,32)$. Increased MMP expression, but reduced TIMP expression, were also found in several HCC cell lines with high metastatic potential $(21,22,34)$ including MHCC $97 \mathrm{H}$ cells. Furthermore, increased TIMP expression reduced invasion and metastasis of cancer cells $(5,27)$, indicating that TIMP exert antimetastatic effects in cancer. In this study, in $\mathrm{MHCC} 97 \mathrm{H}$ cells, the effect of CIE on TIMP-1 and TIMP-2 mRNA, protein and enzyme activity was determined at the same time by RTPCR, Western blot and reverse zymography analysis, respectively. As illustrated in Figs. 5 and 6, CIE could enhance TIMP-1 and TIMP-2 expression in MHCC97H cells in a dose-dependent manner, indicating CIE treatment of HCC could act as a potential anti-metastatic effect involving TIMPs.

Under physiologic conditions, the regulation of MMPs and TIMPs that could be bound with the active site of MMPs in the ratio of $1: 1$, in normal cells and tissue, maintain their dynamic equilibrium (27). However, it has been proposed that for basement membrane and ECM degradation, and ultimately invasion and metastasis to occur, alterations exist in the relative levels of MMPs to their associated TIMPs leading to an imbalance causing increased type IV collagen degradation $(30,32)$. The metalloproteinases that degrade type IV collagen, the principal component of the basement membrane, include MMP-2 and MMP-9 and their inhibitors TIMP-2 (for MMP-2) and TIMP-1 (for MMP-9) (30). Moreover, previous studies have displayed that the MMP: TIMP ratio in cancer cells was $\sim 1$ that corresponded to cancers of good prognosis $(27,30)$. Based on the evidence above, it is proposed that restoring impairment of MMPs/TIMPs could exert anti-metastasis effect on cancer cells. Our experiments demonstrated that CIE inhibits cancer cell invasion by suppressing MMP-2 and MMP-9 expression and by enhancing TIMP-1 and TIMP-2 expression, simultaneously. To combine the effects of CIE the decreased MMP expression and the increased TIMP expression, as shown in representatively for MMP-2/TIMP-2 and MMP-9/ TIMP-1 (Fig. 7), our present results indicate that CIE could reverse the balance of the ratio between MMPs and TIMPs.

Collectively, at least in part, the results suggest that CIE contributes to a recuperation of the molar ratio imbalance between MMPs and TIMPs by decreasing expression of MMPs but augmenting expression of TIMPs. These phenomena indicate that CIE decreases invasion of hepatocellular carcinoma via regulation of MMP/ TIMP balance as therapeutic target.

In summary, the present study indicated that CIE inhibited the invasion and migration ability of MHCC $97 \mathrm{H}$ cells, as assesses through a Matrigel-coated membrane invasion. These findings also showed that CIE could reduce cancer cell metastatic ability, in part at least, through decrease of the MMP expression, simultaneous increase of the TIMP expression, and further restoring their balance as a therapeutic target in HCC. Chrysanthemum indicum extract could be a novel therapeutic natural product for treatment of $\mathrm{HCC}$ or cancer invasion and metastasis without side effects or cytotoxicity.

\section{Acknowledgements}

This work was supported by a grant from the National Natural Science Foundation of China, No. 30672766 and Science and Technology Developing Project Foundation of Shaanxi Province, No. 2006K16-G4 (1).

\section{References}

1. Huang GW, Tao YM and Ding X: Endocan expression correlated with poor survival in human hepatocellular carcinoma. Dig Dis Sci 54: 389-394, 2007.

2. Bao W, Pan H, Lu M, Ni Y, Zhang R and Gong X: The apoptotic effect of sarsasapogenin from Anemarrhena asphodeloides on HepG2 human hepatoma cells. Cell Biol Int 31: 887-892, 2007. 
3. Yin W, Deng XK, Yin FZ, Zhang XC and Cai BC: The cytotoxicity induced by brucine from the seed of Strychnos nux-vomica proceeds via apoptosis and is mediated by cyclooxygenase 2 and caspase 3 in SMMC 7221 cells. Food Chem Toxicol 45: 1700-1708, 2007.

4. Song HY, Liu YK, Feng JT, et al: Proteomic analysis on metastasis-associated proteins of human hepatocellular carcinoma tissues. J Cancer Res Clin Oncol 132: 92-98, 2006.

5. Kang JH, Han IH, Sung MK, et al: Soybean saponin inhibits tumor cell metastasis by modulating expressions of MMP-2, MMP-9 and TIMP- 2. Cancer Lett 261: 84-92, 2008.

6. Hu YH, Yu LJ, Shao ED, Wu JL and Ji JW: The regulating role of mutant IkappaBalpha in expression of TIMP-2 and MMP-9 in human glioblastoma multiform. Chin Med J (Engl) 122: 205-211, 2009.

7. Figueira RC, Gomes LR, Neto JS, Silva FC, Silva ID and Sogayar MC: Correlation between MMPs and their inhibitors in breast cancer tumor tissue specimens and in cell lines with different metastatic potential. BMC Cancer 9: 20, 2009.

8. Wang L, Zhou GB, Liu P, et al: Dissection of mechanisms of Chinese medicinal formula Realgar-Indigo naturalis as an effective treatment for promyelocytic leukemia. Proc Natl Acad Sci USA 105: 4826-4831, 2008.

9. Song TY, Lin HC, Yang NC and Hu ML: Antiproliferative and antimetastatic effects of the ethanolic extract of Phellinus igniarius (Linnearus: Fries) Quelet. J Ethnopharmacol 115: 50-56, 2008.

10. Van Slambrouck S, Daniels AL, Hooten CJ, et al: Effects of crude aqueous medicinal plant extracts on growth and invasion of breast cancer cells. Oncol Rep 17: 1487-1492, 2007.

11. Weng CJ, Chau CF, Yen GC, Liao JW, Chen DH and Chen KD: Inhibitory effects of ganoderma lucidum on tumorigenesis and metastasis of human hepatoma cells in cells and animal models. J Agric Food Chem 57: 5049-5057, 2009.

12. Norikura T, Kojima-Yuasa A, Shimizu M, et al: Mechanism of growth inhibitory effect of Blumea balsamifera extract in hepatocellular carcinoma. Biosci Biotechnol Biochem 72: 1183-1189, 2008.

13. Bae SJ and Choi YH: Methanol extract of the seaweed Gloiopeltis furcata induces $\mathrm{G} 2 / \mathrm{M}$ arrest and inhibits cyclooxygenase-2 activity in human hepatocarcinoma HepG2 cells. Phytother Res 21: $52-57,2007$

14. Cheon MS, Yoon T, Lee do Y, et al: Chrysanthemum indicum Linné extract inhibits the inflammatory response by suppressing NF-kappaB and MAPKs activation in lipopolysaccharideinduced RAW 264.7 macrophages. J Ethnopharmacol 122: 473-477, 2009

15. Lee do Y, Choi G, Yoon T, Cheon MS, Choo BK and Kim HK: Anti-inflammatory activity of Chrysanthemum indicum extract in acute and chronic cutaneous inflammation. J Ethnopharmacol 123: 149-154, 2009

16. Wang ZD, Liang RR and Li ZF: Development in pharmacological research of Chrysanthemum indicum. Medical Recapitulate 15: 906-909, 2009

17. Li ZF, Wang ZD, Ji YY, Zhang S, Huang C, Li J and Xia XM: Induction of apoptosis and cell cycle arrest in human hepatocellular carcinoma MHCC $97 \mathrm{H}$ cells with Chrysanthemum indicum extract. World J Gastroenterol 15: 4538-4546, 2009.

18. Xiang LP, Ouyang H and Xiao YL: The clinical observation of Juzao pill antitumor on postoperative breast cancer with recurrence and metastasis. Chin J Clin Pharmacol Therapeut 7 : 63-64, 2002.

19. Bi X, Song XL and Zhang JZ: Analysis of xiaoliu formula treatment of esophageal carcinoma patients with advanced stage. Chinese Traditional Patent Medicine 30: 1266-1268, 2008 .
20. Wang Z, Zhou J, Fan J, et al: Sirolimus inhibits the growth and metastatic progression of hepatocellular carcinoma. J Cancer Res Clin Oncol 135: 715-722, 2009.

21. Huang XY, Wang L, Huang ZL, Zheng Q, Li QS and Tang ZY: Herbal extract 'Songyou Yin' inhibits tumor growth and prolongs survival in nude mice bearing human hepatocellular carcinoma xenograft with high metastatic potential. J Cancer Res Clin Oncol 135: 1245-1255, 2009.

22. Ji XN, Ye SL, Li Y, et al: Contributions of lung tissue extracts to invasion and migration of human hepatocellular carcinoma cells with various metastatic potentials. J Cancer Res Clin Oncol 129: 556-564, 2003.

23. Liu FJ, Gui SB, Li CZ, Sun ZL and Zhang YZ: Antitumor activity of F90, an epidermal growth factor receptor tyrosine kinase inhibitor, on glioblastoma cell line SHG-44. Chin Med J (Engl) 121: 1702-1706, 2008.

24. Cha BY, Park CJ, Lee DG, et al: Inhibitory effect of methanol extract of Euonymus alatus on matrix metalloproteinase-9. J Ethnopharmacol 85: 163-167, 2003.

25. Qian YF, Wang $H$, Yao WB and Gao XD: Aqueous extract of the Chinese medicine, Danggui-Shaoyao-San, inhibits apoptosis in hydrogen peroxide-induced PC 12 cells by preventing cytochrome c release and inactivating of caspase cascade. Cell Biol Int 32: 304-311, 2008

26. Hwang ES and Lee HJ: Benzyl isothiocyanate inhibits metalloproteinase-2/-9 expression by suppressing the mitogen-activated protein kinase in SK-Hep1 human hepatoma cells. Food Chem Toxicol 46: 2358-2364, 2008

27. Yao Z and Shulan Z: Inhibition effect of Guizhi-Fuling-decoction on the invasion of human cervical cancer. J Ethnopharmacol 120: 25-35, 2008

28. Hayasaka A, Suzuki N, Fujimoto N, Iwama S, Fukuyama E, Kanda $\mathrm{Y}$ and Saisho H: Elevated plasma levels of matrix metalloproteinase-9 (92-kd type IV collagenase/gelatinase B) in hepatocellular carcinoma. Hepatology 24: 1058-1062, 1996.

29. Arii S, Mise M, Harada T, et al: Overexpression of matrix metalloproteinase 9 gene in hepatocellular carcinoma with invasive potential. Hepatology 24: 316-322, 1996.

30. McKenna GJ, Chen Y, Smith RM, et al: A role for matrix metalloproteinases and tumor host interaction in hepatocellular carcinomas. Am J Surg 183: 588-594, 2002.

31. Ha KT, Kim JK, Kang SK, Kim DW, Lee YC, Kim HM and Kim CH: Inhibitory effect of Sihoga-Yonggol-Moryo-Tang on matrix metalloproteinase-2 and-9 activities and invasiveness potential of hepatocellular carcinoma. Pharmacol Res 50: 279-285, 2004 .

32. Giannelli G, Bergamini C, Marinosci F, et al: Clinical role of MMP-2/TIMP-2 imbalance in hepatocellular carcinoma. Int J Cancer 97: 425-431, 2002

33. Lee SJ, Cho YH, Park K, et al: Inhibitory effects of the aqueous extract of Magnolia officinalis on the responses of human urinary bladder cancer 5637 cells in vitro and mouse urinary bladder tumors induced by N-Butyl-N-(4-hydroxybutyl) nitrosamine in vivo. Phytother Res 23: 20-27, 2009.

34. Kim JR and Kim CH: Association of a high activity of matrix metalloproteinase- 9 to low levels of tissue inhibitors of metalloproteinase-1 and -3 in human hepatitis B-viral hepatoma cells. Int J Biochem Cell Biol 36: 2293-2306, 2004. 